The epidemic started during the winter, and the highest number of cases were recorded in the months of June and July (due to the increased activity of both animals and humans, acting as infection reservoirs and hosts). The epidemic spread throughout most of Croatia. The known natural foci of hemorrhagic fever with renal syndrome have been the Plitivice and Slunj areas, Dinara Mountain, Velika and Mala Kapela mountains, the Zagreb area (Velika Gorica and Jastrebarsko), the Gorski Kotar area (Ogulin, Delnice), west Slavonia, and the Novska area. The disease has not been recorded in the litoral area and the Adriatic islands. The disease was also recorded in the neighboring countries of Slovenia, Bosnia and Herzegovina, Serbia, and Montenegro. The identified causative agents include Dobrava and Puumala, which are viruses of the genus Hantavirus. Rodents, including Clethrionomys glareolus (bank vole), Apodemus flavicollis (yellow-necked field mouse), Apodemus agrarius (black-striped field mouse), and Apodemus sylvaticus (wood mouse), serve as the main reservoirs for the infection in Croatia. Typical biotypes of the infection in Croatia are deciduous woods. The 2002 epidemic confirmed the presumption that most of continental Croatia is a natural focus for hemorrhagic fever with renal syndrome.

The disease usually occurs sporadically; the epidemics frequently accompany armed conflicts. Thus, soldiers are the group at the highest risk in both war and peacetime conditions. Therefore, hemorrhagic fever with renal syndrome is an important disease from the viewpoint of military epidemiology.

Keywords: Croatia; epidemiological characteristics; hemorrhagic

fever with renal syndrome; hosts; reservoirs

Prehosp Disast Med 2003:18:s(1)s20.

E-mail: rosanda.mulic1@st.hinet.hr

\section{Epidemiological Characteristics and Military Significance of $Q$-Fever in Croatia}

Prof. Darko Ropac, $M D, P b D$; Rosanda Mulice, $M D, P b D$

Naval Medical Institute of the Croatian Army, Croatia

Q-fever is an acute, febrile, rickettsial infection spread all over the world. In Croatia, Q-fever poses a considerable and long-standing public health problem. The disease primarily involves certain animal species, which transmit it easily through various routes of exchange. Also, it is commonly spread through dust. Q-fever frequently is present as an enzootic among domestic animals, occurring sporadically in occupationally exposed individuals.

Over the last 10 years (1992-2001), 406 affected persons ( 40 per year on average) were recorded in Croatia. The real incidence probably exceeds the number of recorded cases because of the frequently mild clinical picture, absence of suspicion of the disease, and inadequate laboratory diagnostic testing. In recent years, epidemic outbreaks of $Q$-fever with a high number of affected individuals over a relatively small area were observed. Although the agent causing $Q-$ fever replicates only in living cells, like sporogenic bacteria, it is highly resistant to unfavorable environmental conditions and to most of the widely used disinfectants. It can survive for a year in a desiccated biological material at a low temperature. It can also survive for a year and a half in sapless tick feces, or for two years in an infected tick. In the soil, the agent remains infective for seven to nine months at $4-6{ }^{\circ} \mathrm{C}$, and in water for three to 36 months.

Epidemiological data are of great diagnostic importance, because the disease is highly occupation related. Data on a person's stay in a known endemic area or on contact with domestic or wild animals, especially sheep or related animals during the period of lambing, are of utmost importance. However, considering the high agent resistance, transmission of the disease does not require direct human exposure to the infectious material.

Epidemic outbreaks of the disease can occur quite easily in army units staying outdoors, in camps or for training. As there is no routinely used vaccination for either humans or animals, and as Croatia has a very long border with Bosnia and Herzegovina, where there is a known problem of $\mathrm{Q}-\mathrm{fever}$ in sheep, the occurrence of the disease cannot be completely prevented. While staying outdoors, army units should avoid endemic areas, sleeping in barns, and any contact with sheep. For the rest of the population, the risk of infection can be reduced by close cooperation with veterinary services and public health institutions. If an epidemic breaks out, control measures are limited to the elimination of the sources of the infection, monitoring of the exposed group, isolation of the affected, and antibiotic therapy.

Keywords: army; Croatia; epidemics; incidence; outdoors; prevention; Q-fever; resistance; transmission

Prehosp Disast Med 2003:18:s(1)s20.

E-mail: rosanda.mulic1@st.hinet.hr

\section{HIV/AIDS in Complex Emergencies: The Role of Military and Peacekeepers \\ Dr. Manuel Carballo; ${ }^{1}$ Mrs. Pamela Delargy ${ }^{2}$ \\ 1. ICMH \\ 2. UNFPA}

In recent years, wars and complex emergencies have become increasingly common, especially in least developed areas of the world, where the impact of HIV/AIDS has been most pronounced. There is growing evidence that wars and complex emergencies produce the type of conditions that can facilitate the spread of HIV/AIDS. Social disorganization, family disruption, displacement, breakdown of protection, and gender and sexual abuse are some of the contributing factors. In many parts of the world, military personnel and peacekeepers are especially at risk for HIV/AIDS, and also find themselves in social settings in which they also can contribute to the spread of HIV/AIDS. Both military personnel and peacekeepers nevertheless may be a potential force in the prevention of HIV/AIDS as well as other health problems. The ICMH and UNFPA are collaborating with sub-Saharan African countries to explore what new roles and capacities military and peacekeeping personnel could assume, and are using a combination of training and behavioral monitoring to develop a program with national military authorities and UNDPKO. In Sierra Leone and the DRC, there already is evidence that both groups of uniformed personnel are willing to and capable of playing an outreach role.

Keywords: behavioral monitoring; complex emergencies; contributing factors; HIV/AIDS; military; peacekeeping; prevention; subSaharan Africa; social disorganization; training; war 